\title{
Concepções e práticas de educação e saúde da população negra: uma revisão integrativa da literatura brasileira
}

\author{
Conceptions and practices of education and black population health: an \\ integrative review of Brazilian literature
}

\section{Concepciones y prácticas de educación y salud de la población negra: una revisión integrativa de la literatura brasileña}

Tamiris Pereira Rizzo ${ }^{1, a}$

tami.rizzo16@gmail.com | https://orcid.org/oooo-0oo2-2226-9620

\author{
Alexandre Brasil Carvalho da Fonseca ${ }^{1, b}$ \\ abrasil@ufrj.br | https://orcid.org/o000-0002-7495-4902 \\ ${ }^{1}$ Universidade Federal do Rio de Janeiro. Rio de Janeiro, RJ, Brasil. \\ a Mestrado em Saúde Coletiva pela Universidade Federal de São Paulo. \\ b Doutorado em Sociologia pela Universidade de São Paulo.
}

\section{Resumo}

A Política de Saúde Integral da População Negra reiterou a urgência de qualificação dos processos educativos no Sistema Único de Saúde (SUS) em prol da superação do racismo institucional. A revisão integrativa, apresentada neste artigo, analisou as concepções teóricas e as práticas educativas em estudos dirigidos à saúde da população negra. Foram utilizadas as bases de dados da Biblioteca Virtual em Saúde (BVS); a Scientific Eletronic Library Online (SciELO); a ferramenta de pesquisa na web Google Scholar e o acervo da revista da Associação Brasileira de Pesquisadores/as Negros/as, a Revista da ABPN. A produção na temática é heterogênea, dispersa entre periódicos das áreas da educação, educação em saúde e interdisciplinar. Há vanguardismo da enfermagem e forte presença de estudos com povos e comunidades tradicionais. Nota-se dificuldade de interpenetração de referenciais teóricos e pedagógicos do campo da educação na sustentação das práticas educativas de saúde. Sugerem-se a cooperação e a integração científica entre esses campos visando ao protagonismo do sujeito negro nos processos de cuidado.

Palavras-chave: Educação em saúde; Saúde da população negra; Direitos territoriais; Equidade em saúde; Racismo. 


\section{Abstract}

The Política de Saúde Integral da População Negra (Integral Health Policy of the Black Population) reiterated the urgency of qualifying educational processes in the Unified Health System (SUS - Sistema Único de Saúde) in order to overcome institutional racism. The integrative review presented in this article analyzed the theoretical conceptions and the educational practices in studies directed to the health of the black population. The databases of the Virtual Health Library (VHL); the Scientific Electronic Library Online (SciELO); the web search engine Google Scholar and the collection of the Revista da ABPN that is the magazine of the Associação Brasileira de Pesquisadores/as Negros/as (Brazilian Association of Black Researchers) were examined. The production in this thematic is heterogeneous, dispersed in periodicals of the areas of education, health education and interdisciplinary. When the matter is the health of black population, the nursing is an avantgarde profession carrying out a number of studies with traditional peoples and communities. It was noted the difficulty of interpenetration of theoretical and pedagogical references of the field of education in support of educational health practices. We suggest the cooperation and the scientific integration between these fields aiming at the protagonism of the black population in the process of care.

Keywords: Health education; Health of the black population; Lang rights; Equity in health; Racism.

\section{Resumen}

La Política de Saúde Integral da População Negra (Política de Salud Integral de la Población Negra) reiteró la urgencia de calificación de los procesos educativos en el Sistema Único de Salud (SUS - Sistema Único de Saúde) en pro de la superación del racismo institucional. La revisión integrativa, presentada en este artículo, analizó las concepciones teóricas y las prácticas educativas en estudios dirigidos a la salud de la población negra. Se utilizaron las bases de datos de la Biblioteca Virtual en Salud (BVS); la Scientific Eletronic Library Online (SciELO); el motor de búsqueda web Google Scholar y el acervo de la Revista da ABPN, la cual es la revista de la Associação Brasileira de Pesquisadores/as Negros/as (Asociación Brasileña de Investigadores/ as Negros/as. La producción en la temática es heterogénea, dispersa entre periódicos del área de la educación, educación en salud y interdisciplinaria. La enfermería se destaca en la literatura acerca de la salud de la población negra en la cual hay fuerte presencia de estudios con pueblos y comunidades tradicionales. Se observa dificultad de interpenetración de referenciales teóricos y pedagógicos del campo de la educación en la sustentación de las prácticas educativas de salud. Proponemos la cooperación y la integración científica entre esos campos visando el protagonismo del sujeto negro en los procesos de cuidado.

Palabras clave: Educación en salud; Salud de la población negra; Derecho a la tierra; Equidad en salud; Racismo.

INFORMAÇÕES DO ARTIGO

Contribuição dos autores:

Concepção e desenho do estudo: Tamiris Pereira Rizzo e Alexandre Brasil Carvalho da Fonseca.

Aquisição, análise ou interpretação dos dados: Tamiris Pereira Rizzo.

Redação do manuscrito: Tamiris Pereira Rizzo.

Revisão crítica do conteúdo intelectual: Alexandre Brasil Carvalho da Fonseca.

Declaração de conflito de interesses: não há.

Fontes de financiamento: o presente trabalho foi realizado com apoio da Coordenação de Aperfeiçoamento de Pessoal de Nível Superior - Brasil (CAPES) - Código de Financiamento 001.

Considerações éticas: esta revisão vincula-se a um projeto pesquisa aprovado sob número 12563219.4.0000.5286 no Comitê de Ética em Pesquisa.

Agradecimentos/Contribuições adicionais: não há.

Histórico do artigo: submetido: 3 dez. 2018 | aceito: 15 jul. 2019 | publicado: 20 dez. 2019.

Apresentação anterior: não houve.

Licença CC BY-NC atribuição não comercial. Com essa licença é permitido acessar, baixar (download), copiar, imprimir, compartilhar, reutilizar e distribuir os artigos, desde que para uso não comercial e com a citação da fonte, conferindo os devidos créditos de autoria e menção à Reciis. Nesses casos, nenhuma permissão é necessária por parte dos autores ou dos editores. 


\section{Introdução}

A Política Nacional de Saúde Integral da População Negra, promulgada em 2006, representou um marco fundamental para o reconhecimento do racismo e das repercussões das desigualdades e iniquidades étnico-raciais como determinantes das condições de saúde de negros e negras, canalizando, assim, importantes proposições acerca da superação do racismo institucional no âmbito do Sistema Único de Saúde (SUS)․․

Entre os objetivos da política, cabe destacar a necessidade de desenvolver "[...] processos de informação, comunicação e educação que desconstruam estigmas e preconceitos, fortaleçam uma identidade negra positiva e contribuam para a redução das vulnerabilidades". Dessa forma, são estimuladas ações que visem à inserção da temática nos processos de formação e educação permanente dos profissionais de saúde, reforçando a reorientação das estratégias de cuidado e de educação nessa área a partir do reconhecimento dos "[...] saberes e práticas populares de saúde, incorporando inclusive aqueles preservados pelas religiões de matrizes africanas"1.

Historicamente é possível identificar, na constituição e trajetória do campo da educação em saúde, concepções e estratégias educativas que, em diversos momentos e segundo diferentes ideários sociais, estiveram a serviço de aprofundar a discriminação étnico-racial e afastar a população negra dos serviços de saúde oficiais.

No período colonial (séculos XVI-XIX), observa-se a força da ordem jesuítica na construção de uma pedagogia catequizadora e autoritária sobre os hábitos de saúde da população negra e indígena. Embora os cuidados com tal finalidade mais disseminados nesse período fossem aqueles vinculados à sabedoria ritualística e à combinação de ervas em diversas técnicas terapêuticas, a ação empregada pela ordem os qualificava como diabólicos. Sendo assim, atuava de forma a separar a medicina 'pagã' do que viria a ser a medicina oficial² .

Ademais, o pensamento médico brasileiro passava a vincular as principais doenças do século XIX ao tráfico de escravos africanos, disseminando abertamente pressupostos eugenistas na saúde. Destaca-se a produção de dezenas de manuais educativos, entre os anos de 1834 e 1873, dirigidos aos senhores de escravos baseados em condutas terapêuticas impregnadas de intuitos civilizatórios, educação moral e higienista do escravizado, como sinaliza Porto ${ }^{3}$.

O mesmo verifica-se nos trabalhos de Kodama ${ }^{4,5}$, analisando os discursos abolicionistas no jornal O Philantropo (1849-1852) e as correlações estabelecidas entre raça e doença, ou ainda verificando as estratégias de combate à epidemia de febre amarela na Europa e a repercussão destas no surto da doença em 1850, no Brasil, veiculado na imprensa como 'Febre Africana'.

O fim da escravidão e o início do período republicano, no início do século $\mathrm{XX}$, despertaram profundos debates sobre a constituição de um projeto de estado-nação brasileiro e a busca por uma identidade nacional. Nessa seara, as teses eugênicas passam a conferir substância à política de imigração europeia, com a expectativa de promover um processo de homogeneização e harmonização racial a partir do ideal de branqueamento da população $0^{6}$.

Esse momento, que culminou na defesa da mestiçagem como processo espontâneo e harmonioso7, guarda importantes marcas na transformação dos debates acerca das ações de educação em saúde para a população negra, especialmente aquelas vinculadas à saúde reprodutiva das mulheres ${ }^{8}$.

O estudo de Damasco, Maio e Monteiro9 expõe as contradições presentes nas ações das autoridades de saúde e nos enfrentamentos promovidos pelo movimento de feministas negras. As autoras evidenciam que, mesmo diante de taxas de fecundidade inferiores (períodos 1940-60) e menor número de uniões estáveis, casamento e celibato tardio (1960-80) entre negras em relação às brancas, as campanhas dirigidas à educação sexual e reprodutiva eram evidentemente racistas, estimulando esterilizações em prol do embranquecimento da população. 
Destaca-se o caso emblemático da campanha publicitária promovida pelo Centro de Pesquisa e Assistência em Reprodução Humana, em 1986: "Nessa campanha [de divulgação do CEPARH] era um outdoor que ele [Elsimar Coutinho] distribuiu pela cidade de Salvador, em que se mostrava uma cena de necrotério, com uma criança de cinco anos, em pé, ao lado de um cadáver que estava coberto e aparecia o pé de uma mulher negra, uma criança negra e os dizeres eram: 'Defeito de fabricação - Planejamento familiar, procure o Centro de Assistência e Reprodução Humana"”.

De modo análogo ao que foi explorado em outro artigo ${ }^{10}$, essa perspectiva fundamentada em discriminações étnico-raciais permaneceu de forma significativa no decorrer do Estado Novo e, conforme esta revisão indica, ainda encontra reverberação nos dias atuais. Esses exemplos históricos retratam a herança desafiadora para o campo da educação em saúde na perspectiva dos direitos à universalidade, integralidade e equidade no âmbito do SUS para a população negra.

A verticalização, o autoritarismo e a discriminação social e étnico-racial compuseram ferramentaschave na implementação de um projeto ideológico racista que, servindo-se de uma pedagogia da opressão, submeteram à lógica da colonialidade do poder saberes ancestrais que vinculavam identidade, espiritualidade, cultura e autonomia nas práticas de cuidado e de educação em saúde ${ }^{11,12}$.

Este artigo de revisão integrativa, portanto, teve como objetivo reunir e analisar de que forma as concepções e práticas educativas estão sendo abordadas nos estudos relacionados à saúde da população negra no âmbito da educação em saúde ${ }^{13}$.

\section{Metodologia}

A revisão foi orientada pelas seguintes perguntas de pesquisa: a) como as concepções educativas se apresentam nos estudos de campo relacionados à saúde da população negra?; e b) de que forma a temática se localiza na produção científica do campo de educação em saúde? Após a definição das questões norteadoras, foi realizada uma busca exploratória nos principais portais e bases de dados visando à experimentação das equações de pesquisa.

Tendo em vista o interesse em mapear a produção nacional, bem como sua distribuição no tempo, foram utilizados dois Descritores em Ciências da Saúde (DeCS), 'Educação em Saúde' e 'Grupo com Ancestrais do Continente Africano', localizados em qualquer parte do texto, na modalidade artigo científico avaliado por pares, com texto completo disponível e com o Brasil como país de origem. Não foi realizada especificação de ano de publicação, coleções, área temática ou periódicos. Por sua vez, a pesquisa foi padronizada com os DeCS nas bases de dados da Biblioteca Virtual em Saúde (BVS), da Scientific Eletronic Library Online (SciELO), da ferramenta Google Scholar e dos Periódicos Capes.

Posteriormente, foi incluído o acervo da revista da Associação Brasileira de Pesquisadores/as Negros/as, a Revista da ABPN, por se tratar de publicação de referência na temática racial. Por não oferecer a possibilidade de inclusão de mais de um descritor, foi utilizada somente a palavra-chave 'saude' em todas as publicações do acervo da revista (2010-2017). O software Endnote $^{\mathrm{R}}$ foi utilizado para a organização do banco de dados.

Após a extração de 52 artigos, provenientes das bases de dados BVS (10), SciELO (02), Google Scholar (12), Capes (02), ABPN (26), realizou-se a exclusão de trabalhos duplicados com base nos seguintes critérios: a) não se tratar da modalidade artigo científico; b) não apresentar texto completo disponível; c) relacionarse à população negra apenas como perfil de grupo populacional, sem apresentar reflexões sobre a temática de interesse e/ou dos objetivos da revisão; d) originar-se de pesquisa exclusivamente documental, sem apresentar o procedimento de estudo de campo, seja ele com ou sem intervenção educativa; e e) originar-se de periódicos que não apresentassem classificação Qualis Capes no último quadriênio (2013-2016), nas áreas de ensino, educação ou interdisciplinar. 
Os artigos selecionados foram lidos na íntegra, sendo analisados e agrupados segundo os pressupostos da pesquisa qualitativa, buscando contemplar as perguntas norteadoras. O levantamento bibliográfico ocorreu nos meses de novembro e dezembro de 2017, prosseguido de análise e escrita do artigo em 2018.

\section{Resultados}

\section{Perfil da produção científica}

O corpus da revisão contemplou oito artigos publicados de forma heterogênea entre os anos de 2010 e 2017. Quanto ao perfil geral da produção, é possível observar a tendência à dispersão nas áreas temáticas, abrangendo periódicos nas áreas de saúde (com destaque para enfermagem), educação em saúde e interdisciplinar. Assim, para efeitos de comparação do fator de impacto, optou-se por selecionar as seguintes áreas temáticas: ensino, educação, interdisciplinar e a de especialidade da revista.

O agrupamento dos estudos entre si originou as seguintes categorias: a) Estudos com intervenção educativa ( $n=03)$; b) Estudos de concepção, valores e significados para educação em saúde (n=04); e c) Estudos sobre educação continuada e permanente dos profissionais de saúde ( $n=1)$, categorias estas similares às encontradas por Casotti, Brant, Pimenta e Nespoli ${ }^{13}$.

No que diz respeito ao local de produção dos artigos, observa-se a preponderância da região Sul do Brasil. A temática abordada nos estudos foi heterogênea, cabendo destacar a predominância de pesquisas realizadas em comunidades tradicionais quilombolas (04) e comunidades de terreiro (03), sendo uma delas com interface nos serviços de saúde e apenas um em comunidade universitária (o1). Quanto à modalidade, foram encontrados estudos descritivos (04), estudos de intervenção (01), relato de experiência (02) e estudo etnográfico (01). Estes resultados podem ser melhor observados no Quadro 1:

Quadro 1- Perfil da produção científica do corpus da revisão

(continua)

\begin{tabular}{|c|c|c|c|c|c|c|}
\hline $\begin{array}{l}\text { Modalidade } \\
\text { de estudo }\end{array}$ & Identificação & Autores & Periódico & Qualis & Ano & $\begin{array}{l}\text { Modalidade de } \\
\text { estudo }\end{array}$ \\
\hline \multirow{2}{*}{$\begin{array}{l}\text { Estudo de } \\
\text { intervenção }\end{array}$} & 01 & $\begin{array}{l}\text { Gomes, } \\
\text { MCPA. }\end{array}$ & $\begin{array}{l}\text { Interface - } \\
\text { Comunicação, } \\
\text { Saúde, } \\
\text { Educação }\end{array}$ & $\begin{array}{l}\text { Ensino A1 Educação } \\
\text { A2 Interdisciplinar } \\
\text { A2 }\end{array}$ & 2010 & Relato de experiência \\
\hline & 02 & $\begin{array}{l}\text { Menezes } \\
\text { RCTD et al. }\end{array}$ & $\begin{array}{l}\text { Escola Anna } \\
\text { Nery Revista de } \\
\text { Enfermagem }\end{array}$ & $\begin{array}{l}\text { Ensino A2 Educação } \\
\text { B1 Interdisciplinar } \\
\text { B1 Enfermagem B1 }\end{array}$ & 2015 & Relato de experiência \\
\hline $\begin{array}{l}\text { Categorias } \\
\text { analíticas }\end{array}$ & Identificação & Autores & Periódico & Qualis & Ano & $\begin{array}{l}\text { Modalidade de } \\
\text { estudo }\end{array}$ \\
\hline $\begin{array}{l}\text { Estudo de } \\
\text { intervenção }\end{array}$ & 03 & $\begin{array}{l}\text { Passos TS } \\
\text { et al. }\end{array}$ & $\begin{array}{l}\text { Revista de } \\
\text { Enfermagem } \\
\text { UFPE-Online }\end{array}$ & $\begin{array}{l}\text { Ensino B5 Educação } \\
\text { B3 Interdisciplinar } \\
\text { B4 Enfermagem B2 }\end{array}$ & 2017 & Estudo de intervenção \\
\hline
\end{tabular}


(conclusão)

\begin{tabular}{|c|c|c|c|c|c|c|}
\hline $\begin{array}{l}\text { Categorias } \\
\text { analíticas }\end{array}$ & Identificação & Autores & Periódico & Qualis & Ano & $\begin{array}{l}\text { Modalidade de } \\
\text { estudo }\end{array}$ \\
\hline \multirow{4}{*}{$\begin{array}{l}\text { Estudos de } \\
\text { concepções, } \\
\text { valores e } \\
\text { significados } \\
\text { para } \\
\text { educação em } \\
\text { saúde }\end{array}$} & 04 & $\begin{array}{l}\text { Bidinotto AB } \\
\text { et al. }\end{array}$ & $\begin{array}{l}\text { Revista } \\
\text { Brasileira de } \\
\text { Epidemiologia }\end{array}$ & $\begin{array}{l}\text { Ensino B3 } \\
\text { Interdisciplinar B1 } \\
\text { Saúde Coletiva B1 }\end{array}$ & 2017 & Estudo descritivo \\
\hline & 05 & Lages SRC. & $\begin{array}{l}\text { Psicologia } \\
\text { Argumento }\end{array}$ & $\begin{array}{l}\text { Educação B2 } \\
\text { Interdisciplinar B2 } \\
\text { Psicologia B2 }\end{array}$ & 2012 & Estudo descritivo \\
\hline & 06 & $\begin{array}{l}\text { Silveira CL } \\
\text { et al. }\end{array}$ & $\begin{array}{l}\text { Ciência, } \\
\text { Cuidado e } \\
\text { Saúde }\end{array}$ & $\begin{array}{l}\text { Ensino B4 Educação } \\
\text { B2 Interdisciplinar } \\
\text { B4 Enfermagem B2 }\end{array}$ & 2011 & Estudo descritivo \\
\hline & 07 & $\begin{array}{l}\text { Alves MC, } \\
\text { Seminotti } \\
\text { JPD }\end{array}$ & $\begin{array}{l}\text { Revista da } \\
\text { ABPN }\end{array}$ & $\begin{array}{l}\text { Ensino B4 Educação } \\
\text { B5 Interdisciplinar } \\
\text { B2 }\end{array}$ & 2017 & Estudo etnográfico \\
\hline $\begin{array}{l}\text { Estudo sobre } \\
\text { educação } \\
\text { continuada/ } \\
\text { permanente } \\
\text { com } \\
\text { profissionais } \\
\text { de saúde }\end{array}$ & 08 & $\begin{array}{l}\text { Mendes VS } \\
\text { et al. }\end{array}$ & $\begin{array}{l}\text { Revista da } \\
\text { ABPN }\end{array}$ & $\begin{array}{l}\text { Ensino B4 Educação } \\
\text { B5 Interdisciplinar } \\
\text { B2 }\end{array}$ & 2015 & Estudo descritivo \\
\hline
\end{tabular}

Fonte: Os autores (2018).

Em razão da diversidade temática, os artigos são apresentados brevemente a seguir, buscando explorar potencialidades e limitações. Na categoria de estudos com intervenções educativas, buscou-se dar centralidade à prática educativa, assim como à sua formulação, aos seus referenciais teóricos e/ou pedagógicos, ao seu planejamento e à sua execução. Nas outras duas categorias, priorizou-se o mapeamento dos embasamentos adotados. No corpo do artigo, a referência aos autores dos estudos analisados é acompanhada, entre colchetes, do número com o qual eles são identificados no Quadro 1. No final de cada seção, encontram-se, sistematizados, o conjunto dos achados.

\section{Estudos com intervenções educativas}

O estudo de Gomes ${ }^{14}$ [01] trata da experiência de um serviço de atenção básica de saúde do Rio de Janeiro perante a auto-organização de 75 mulheres negras de santo que, diante das dificuldades de acesso ao e de equidade no atendimento, reivindicavam a abertura de um posto de vacinação em espaço cedido pelo terreiro.

O percurso da implementação de um consultório em tal lugar contou com três etapas: (i) revisão de literatura na temática 'raça, saúde e religiosidade'; (ii) questionário para cadastramento e avaliação do perfil dos usuários; e (iii) estudos para planejamento e organização do serviço.

Entre os achados, ressalta-se o efeito positivo causado pela participação social das mulheres no despertar de um olhar problematizador dos profissionais acerca de práticas de intolerância religiosa e de racismo vivenciadas na unidade básica de referência, no território.

Esse processo culminou na implementação do consultório e na realização de dezenas de atendimentos e de oficinas educativas, com destaque para planejamento familiar e doenças sexualmente transmissíveis (DSTs). Tais oficinas foram inspiradas nos manuais da Estratégia Saúde da Família (ESF) e organizadas com o intuito de formação de multiplicadoras ${ }^{15}$. 
A análise do guia demonstrou tratar-se de publicação geral para o atendimento de rotinas das equipes de ESF. No que tange às ações educativas, o material orienta exclusivamente as temáticas a serem abordadas dentro de cada contexto de atenção à saúde nos ciclos da vida e na prevenção de doenças mais prevalentes na população em geral.

Nesse caso, torna-se mais evidente a contribuição teórica do estudo na forma como a revisão de literatura realizada emerge e se relaciona com a experiência, demonstrando a educação em saúde como um lugar de mediações e diálogo entre profissionais e comunidade em prol de estratégias participativas das políticas públicas, como observa Eymar ${ }^{16}$.

O estudo aponta limitações na sustentabilidade de ações como essas, sobretudo devido à resistência dos profissionais e gestores de saúde, que, por não se sentirem “[...] responsáveis pela desigualdade e pobreza, não apresentam-se (sic) comprometidos/solidários com essas mulheres e suas famílias"14.

Dois estudos ${ }^{17,18}$ [02 e 03] inserem-se em um projeto guarda-chuva denominado 'Perfil epidemiológico das doenças e agravos em comunidades quilombolas de Sergipe'. Atuaram, no entanto, sobre comunidades distintas, sendo o primeiro um estudo de intervenção; e o segundo, um relato de experiência extensionista.

$\mathrm{O}$ estudo de intervenção ${ }^{17}$ objetivou avaliar a efetividade de intervenção educativa na temática do traço e da anemia falciforme, oferecendo orientações quanto ao risco genético, manifestações orais da doença e noções gerais de autocuidado em uma amostra de 230 indivíduos, com aplicação de questionário semiestruturado e análise estatística antes e depois da intervenção educativa.

Seus autores salientam a metodologia criteriosa e os resultados positivos da intervenção educativa. Para fins desta revisão, cabe mencionar a produção de materiais educativos, tais como cartazes sobre as formas de manifestações orais; exposição de figuras sobre as manifestações clínicas e forma de transmissão; e vídeos/slides abordando autocuidado. A atividade contou também com dinâmicas de sorteio de perguntas entre os participantes. Os materiais produzidos foram subsidiados pelo Manual de Educação em Saúde e Autocuidado na Doença Falciforme e pelos pressupostos da 'Carta de Ottawa'.

A análise do manual de referência ${ }^{19}$ demonstrou tratar-se de uma publicação de longo alcance, dirigida aos profissionais de saúde e que oferece orientações gerais e específicas para educação em saúde nas distintas fases da vida para indivíduos falcêmicos e para aqueles que possuem o traço.

Por um lado, a existência do manual atesta os avanços obtidos em torno da intervenção no contexto da anemia falciforme, um dos principais motores pela implementação da política de saúde da população negra ${ }^{20}$. Por outro lado, não se encontraram, no manual, referências do campo da educação que pudessem subsidiar pedagogicamente o planejamento de oficinas com o conjunto das inúmeras orientações fornecidas. Os autores do estudo de intervenção [02] foram contatados em busca de maiores detalhamentos quanto ao planejamento, execução e eventual utilização de autores do campo da educação que sustentassem teórica ou pedagogicamente a prática. No entanto, não se obteve retorno.

O estudo na área de educação para genética, na temática da anemia falciforme, elencou dificuldades no uso do folder educativo do Ministério da Saúde para aconselhamento genético à população com ensino formal deficitário ${ }^{21}$. Dessa forma, inferem-se avanços na elaboração de materiais educativos por parte do Ministério, bem como suas múltiplas estratégias de utilização pelos profissionais. Parece ainda persistir, no entanto, certo distanciamento de autores do campo da educação subsidiando práticas em saúde.

No estudo de relato de experiência extensionista ${ }^{18}$ [03], ocorre uma realidade similar. Trata-se de uma ação educativa, realizada com 111 indivíduos em cinco comunidades quilombolas de Sergipe, voltada para a temática das doenças sexualmente transmissíveis. Na ocasião, foram elaboradas ações educativas antes e após a realização de testes rápidos sobre o Vírus da Imunodeficiência Humana (HIV) e sífilis. Foram utilizados materiais como cartazes e folders, abordando formas de transmissão e estágios das doenças, e realizadas demonstrações quanto ao uso de preservativos. 
O estudo constatou falta de informação e acesso dessas comunidades às ações preventivas contra as Doenças Sexualmente Transmissíveis (DSTs) e dificuldades na obtenção de preservativos nas unidades de saúde. No estudo, são oferecidas poucas informações sobre planejamento, execução e referenciais teóricos e/ou pedagógicos para as ações educativas. Chamam a atenção, entretanto, a presença de $64 \%$ de indivíduos analfabetos ou com ensino fundamental incompleto e a utilização de materiais educativos escritos.

Infere-se tanto em 02 como em o3 que, apesar de se orientarem pelos pressupostos da política de saúde integral da população negra e por publicações de referência que abordam as temáticas de trabalho, há, nas ações, pouco aprofundamento sobre os desafios educativos propriamente ditos, de forma a superar, por um lado, a ação centrada em transmissão de informações, condutas e procedimentos; e, por outro, refletir sobre a abordagem crítica dos conteúdos, incorporando questões como valores, estigmas e concepções nos temas escolhidos.

\section{Estudos de concepções, valores e significados para educação em saúde}

Observa-se, em dois estudos ${ }^{22,23}$ [04 e 06], a utilização da autopercepção como estratégia para descrição dos valores e significados atribuídos por quilombolas à saúde bucal e à condição do sujeito cuidador, respectivamente. A conclusão apontada por essas pesquisas desenvolvidas na região Sul do país sinaliza a necessidade de ações educativas que motivem a população quilombola a adotar as práticas de autocuidado.

À luz das bases tradicionais da epidemiologia, o estudo de Bidinotto e colaboradores [04] ${ }^{22}$ identificou autopercepção negativa de saúde bucal associada à aparência e à eficiência mastigatória na maioria dos(as) chefes de famílias quilombolas (53,7\%). Nesse caso, é possível incorporar como preocupações às práticas educativas em saúde bucal ações preventivas que considerem a temática de sintomas depressivos, déficit cognitivo e insuficiência alimentar como fatores que influenciam a performance mastigatória e a percepção geral sobre a saúde bucal.

Destaca-se, também no estudo $\mathrm{O}^{22}$, a representatividade amostral, com 22 comunidades quilombolas, tendo sido entrevistados 583 chefes de famílias classificados com risco de insegurança alimentar e nutricional moderada e grave. Quanto às limitações, sugere-se, para estudos futuros, que estes venham a subsidiar a temática educativa $\mathrm{e}$ a complementação da abordagem qualitativa, buscando identificar a natureza do suporte oferecido pelos serviços de saúde no que tange à dinâmica de acesso e frequência para assistência nas ações de cuidado e educação, que, embora não tenham sido mencionadas no artigo, já foram constatadas em estudo da área ${ }^{24}$.

Já os resultados encontrados no estudo de Silveira e outros [06 ${ }^{23}$ revelam a importância de se considerarem e estimularem as distintas e complementares formas de apoio social desenvolvidas nas comunidades quilombolas. Assim, faz-se necessária a adoção de referenciais teóricos que considerem o contexto geográfico do quilombo como um potente articulador de identidades, crenças e pertencimentos culturais, fundamentais na composição de uma pedagogia da autonomia para o fazer educativo ${ }^{25}$.

A conclusão do estudo permite inferir que práticas educativas desenvolvidas pelos serviços de saúde deveriam orientar-se pela superação de uma intervenção meramente focada no apoio social informativo, para uma atuação que reconhecesse o potencial da coordenação e integração deste com as possibilidades de apoio emocional/afetivo e instrumental realizado em quilombos. Esta superação orientaria o serviço para integração com e entre mediadores, como a família, grupos de convivência e associações religiosas em ações educativas coletivas, favorecendo a troca de saberes e o enraizamento do serviço de saúde com a rede comunitária.

Quanto à utilização de referenciais teóricos que pudessem fornecer subsídios para concepções e estratégias educativas, encontram-se esclarecimentos apenas no artigo $06^{23}$, que apresenta a contribuição de Bochi e Ângelo ${ }^{26}$, bem como de Valla ${ }^{27}$, na temática do apoio social; e de Anjos e Silva ${ }^{28}$, quanto à importância da articulação entre ancestralidade negra e direitos territoriais.

Nesta mesma categoria, dois estudos ${ }^{29,30}$ [05 e 07] que trabalharam com comunidades tradicionais de terreiro em Juiz de Fora e Porto Alegre, respectivamente, trouxeram apontamentos substanciais acerca dos valores e significados atribuídos à promoção de saúde em comunidades de terreiro. Além disso, 
cabe ressaltar a valorização de pensadores do campo da educação nessas pesquisas, vislumbrando concepções educativas alicerçadas nas áreas de estudos culturais; pós-coloniais e descoloniais; filosofia; e cosmovisão africana.

No artigo de Lages [05] ${ }^{29}$, objetivou-se compreender de que forma e sob quais circunstâncias os saberes do universo religioso umbandista poderiam viabilizar um canal de interlocução entre lideranças religiosas, gestores e profissionais da saúde ${ }^{29}$. Respaldado no conceito de sociologia das ausências, de $\operatorname{Santos}^{31}$, o exame das narrativas de chefes de terreiro mostrou a potência da cosmovisão umbandista frente ao processo saúde-doença, apresentando-se como pensamento de resistência ou pensamento liminar, de acordo com Sonia Lages apud Mignolo ${ }^{32}$.

Os procedimentos terapêuticos complementares ao tratamento feito com médicos, a partir do uso de chás, banhos, água fluidificada significados sob o contexto de acolhimento e escuta atenciosa da figura espiritual do preto-velho, favoreceram, segundo Sonia Lages $^{29}$, o cuidado colaborativo com a medicina tradicional. Deve-se levar em conta que tal prática terapêutica envolve, ainda, íntimo protagonismo do consulente perante as estratégias de cuidado, corroborando uma pedagogia da autonomia ${ }^{25}$.

Por fim, o artigo $05^{29}$ considera o terreiro como um espaço educativo fértil e enraizado em uma cultura própria, porém com fronteiras ancestrais e maleáveis, capazes de resgatar elementos sociais e culturais atrelados ao processo saúde-doença da população negra. Tais fronteiras deveriam ser compreendidas pelos gestores e profissionais da saúde de forma propositiva, oferecendo o exercício da tradução cultural como aporte teórico central para compreensão dos limites e possibilidades para o fazer educativo entres estes campos ${ }^{33}$.

No artigo de Alves, Seminotti e Jesus ${ }^{30}$ [07], resultados semelhantes são encontrados. Esse foi um estudo baseado em uma etnografia com uma comunidade de terreiro de raiz Jêje-Nagô de oitenta anos de existência, contando com 150 adeptos. É identificada a existência de duas questões centrais para fins desta revisão: a constatação de um paradigma civilizatório negro-africano, que localiza a produção de saúde atrelada à própria existência, sendo esta produzida coletiva, objetiva e intersubjetivamente na relação/ categoria de análise 'unidade cósmica e força vital'; e, por outro lado, o seu conflito e o de seus valores, sistemas de ideias e concepções com o paradigma civilizatório ocidental.

Utilizando como referências teóricas o conceito de pensamento complexo, de Morin $^{34}$ e a leitura de Bâ ${ }^{35}$ sobre a cosmologia do paradigma negro-africano, os autores do artigo $07^{30}$ evidenciam, na relação 'bio-mítico-social' e 'sujeito-ancestral-divindade', ambas categorias de análise da pesquisa, a formação das noções de corpo e subjetividade objetivadas por meio de símbolos, imagens e linguagens, característicos da cultura negro-africana e da tradição oral. Esta noção, por sua vez, apareceu na análise do material de campo como capaz de produzir outra concepção de saúde por fora do paradigma civilizatório ocidental.

A história de vida dos atores e autores desta análise recursiva mostrou a procura do terreiro como espaço privilegiado para o cuidado em saúde. Por operar em outro paradigma civilizatório, no entanto, demonstrou-se que a teoria do princípio de corte, de Bastide ${ }^{36}$ pode ter efeito protetivo aos adeptos frente ao contexto social pluricultural, mas também o de produzir fragmentações violentas, as quais poderiam ser enfrentadas, segundo os autores, com a aplicação do princípio da complexificação, de $\operatorname{Morin}^{34}$, na busca de estratégias de recomposição da existência de saberes e práticas promovidos por estas comunidades.

Assim, pode-se inferir que o estudo $07^{30}$ contribui com a temática da educação em saúde, na medida em que traz um rico panorama sobre as noções de produção de saúde nessas comunidades, mas, sobretudo, quando identifica, nos desafios trazidos pelas contradições entre os dois paradigmas, a necessidade de superação de estratégias educativas desprovidas de reflexões teóricas e proposições práticas que se encerram diante das monoculturas do saber ${ }^{37}$.

Coloca-se, então, a urgência de repensar o lugar do saber científico da ciência moderna e de suas práticas educativas, em prol não apenas da legitimação de outras epistemologias, mas do convite a pensar como novas matrizes teóricas e práticas de educação poderiam contemplar, de forma não-periférica, o sistema 
de códigos, valores, ideias e hábitos que significam a vida dos adeptos das religiões de matriz africana a diferentes enfoques e condutas.

\section{Estudos sobre educação continuada/educação permanente dos profissionais de saúde}

Por fim, na última categoria, encontra-se o estudo de Mendes, Costa e Ribeiro ${ }^{38}$ [08]. Produzido a partir de uma dissertação de mestrado no campo da educação, o trabalho buscou analisar, com uma revisão de literatura, as relações étnico-raciais presentes no contexto da constituição da profissão de enfermeiro; e, por meio de 16 entrevistas com docentes de enfermagem de uma universidade pública do Centro-Oeste brasileiro, verificar as implicações do racismo no ensinar e no ensinar-cuidar do paciente negro.

Entre os achados da mencionada pesquisa, destacam-se, para esta revisão, a identificação de diversos referenciais teóricos que explicitam a influência do ideal eugenista sobre a conformação das profissões da saúde, com destaque para a enfermagem. Em que pesem os desafios presentes na constituição de qualquer campo profissional, o artigo sinaliza para os efeitos nocivos, a longo prazo, da adoção do sistema de ensino nightingaleano em um contexto de uma sociedade racista.

Observa-se que, por meio de estratégias de cuidado centradas no modelo biomédico, orientadas para o desenvolvimento de rígidas rotinas, com procedimentos mecânicos, na perspectiva de um olhar disciplinador do corpo, tal sistema de ensino contribuiu para a penetração do ideário eugenista e para a produção de um racismo biológico, presente até hoje, na forma com que enfermeiros(as) percebem e se relacionam com a questão racial.

Os achados do estudo $08^{38}$ contribuem para o campo da educação em saúde, sobretudo da educação permanente, na medida em que identificam, nos discursos de docentes enfermeiros(as), a persistência de uma leitura de dados epidemiológicos de forma desconectada com a interpretação geral do racismo como fato social concreto que influencia os demais indicadores de saúde.

Nesse sentido, é predominante uma leitura por parte desses profissionais cuja ênfase se dá na existência de determinadas doenças que biologicamente afetam mais ou menos pacientes negros(as). Esse aspecto, por sua vez, reflete-se em uma percepção de que características como maior resistência e melhor imunidade sejam inerentes às condições biológicas de pessoas negras, o que implicaria estratégias de cuidado e de educação em saúde diferenciadas, sustentadas, diversas vezes, por uma discriminação biológico-racista.

À luz dos estudos anteriores, verifica-se que o estudo 08 oferece pistas para se compreenderem as dificuldades encontradas nos estudos 01, 02 e 03, todos eles vinculados ao fazer da enfermagem e/ou que têm o enfermeiro como figura central, como no estudo 01, realizado no contexto da atenção básica. Assim, resistências associadas à atuação sobre determinantes sociais e étnico-raciais de saúde aparecem como um caminho pouco familiar desde a formação destes profissionais, de modo que podem refletir sobre a assunção prática da noção de igualdade e equidade no fazer do profissional de enfermagem.

Pode-se inferir que a ausência de referenciais teóricos e pedagógicos do campo da educação para as atividades abordadas nos estudos 02 e 03 revela as consequências dessas possíveis incompreensões. Por um lado, identifica-se a importância do trabalho educativo entre negros(as), e adotam-se as orientações, procedimentos e prescrições adequadas, porém sem incorporar, com fôlego, noções críticas sobre essas próprias condutas e a necessidade de um fazer educativo diferenciado frente ao universo sociocultural de negros(as).

\section{Desafios teóricos e pedagógicos para a educação em saúde da população negra}

Em resposta aos objetivos iniciais desta revisão, no que diz respeito às concepções teóricas que orientam ações de educação em saúde, verificou-se uma dissociação entre a categoria de estudos com intervenção educativa, havendo ausência de referenciais teóricos do campo da educação; e estudos que abordaram concepções, valores e significados das relações étnico-raciais para a saúde, porém sem intervenções educativas. 
Essas dificuldades de interpenetração entre teoria e prática e assimilação da produção teórica da educação nas práticas formativas de saúde parecem refletir as próprias limitações da área de educação em saúde, de forma mais ampla, sem se descartarem impactos específicos, como os assinalados diante da questão racial.

Santili, Tonhom e Marin ${ }^{39}$, examinando as práticas de educação em saúde em equipes do programa Estratégia Saúde da Família, encontrou realidade semelhante, na qual os próprios profissionais que praticam as ações educativas relatam desconhecer o conceito de educação em saúde e dizem possuir "insights de educação". O estudo também aponta ser necessário pensar e discutir o conceito de cultura no escopo das ações de educação em saúde, uma vez que os profissionais relatam dificuldades para lidar com hábitos, valores e concepções culturais dos pacientes e ser esta uma temática pouco abordada na formação.

A dialogicidade como princípio e elemento pedagógico norteador é fundamental, mas não pode ser o único referencial para a construção de propostas de educação em saúde, sobretudo se se considerar a percepção de educação em saúde ${ }^{40}$ como processo e partilha de conhecimentos que favoreçam o exercício autônomo individual e coletivo, buscando a mudança de hábitos em prol de uma melhor qualidade de vida. Isso é ainda mais urgente no recorte específico da população negra, quando se aponta, conforme foi destacado no artigo 08, a falta de discussões e de adoção de conceitos, conteúdos e estratégias mais amplas para desconstrução do pensamento racista que atravessa a formação dos profissionais.

Os estudos que não realizaram intervenções educativas e que continham referenciais teóricos do campo da educação foram predominantemente desenvolvidos em periódicos de natureza multidisciplinar, aspecto que sinaliza a necessidade de maior cooperação científica para futuros estudos na área de educação em saúde da população negra; e que sugere a conformação de equipes interdisciplinares e publicações em periódicos de outras áreas. Cabe salientar também que esses intercâmbios podem favorecer a qualificação do fator de impacto desses estudos, sobretudo nas áreas de ensino, educação e interdisciplinar.

Quanto à natureza das concepções teóricas verificadas, observa-se a predominância de autores que se consagraram na área da educação em saúde, mas também a emergência de outros referenciais que, no campo educacional, dialogam com os estudos culturais e os estudos pós-coloniais/decoloniais.

Assim, sugere-se a formulação de projetos pedagógicos que subsidiem atividades de educação em saúde da população negra, valendo-se da produção científica de ambos os campos. Anseia-se que essa troca possa oferecer outras possibilidades epistemológicas para um fazer em saúde que respeite e valorize outros sistemas de ideias, valores e códigos da cultura afro-brasileira. No Quadro 2, apresenta-se sistematizado o mapeamento dos principais referenciais teóricos nas temáticas/nos conceitos centrais observados nos estudos reunidos.

Quadro 2-Mapeamento dos principais referenciais teóricos dos estudos analisados

\begin{tabular}{|c|c|}
\hline Temáticas/Conceitos centrais & Autores \\
\hline Apoio social & Valla VV27; Bochi SCM, Ângelo M²6 \\
\hline Ancestralidade e direitos territoriais & Anjos JC, Silva ASB28 \\
\hline Sociologia das ausências & Santos BS 31 \\
\hline Colonialidade & Mignolo WD 32 \\
\hline Tradução cultural & Hall $S^{33}$ \\
\hline Pensamento complexo & Morin $\mathrm{E}^{34}$ \\
\hline Filosofia e cosmovisão africana & Bâ $\mathrm{AH}^{35}$ \\
\hline Religiões africanas & Bastide $\mathrm{R}^{36}$ \\
\hline Eugenia e saúde & Rocha HHP41; Mai LD²; Kobayashi E, Faria L, Costa MC ${ }^{43}$. \\
\hline Iniquidades e racismo & $\begin{array}{l}\text { Cotta MM, Gomes AM, Maia TM, Magalhães KA, Marques ES, } \\
\text { Siqueira-Batista } \mathrm{R}^{44} \text {; Lopes } \mathrm{F}^{45}\end{array}$ \\
\hline
\end{tabular}

Fonte: Os autores (2018). 
No que diz respeito às práticas educativas, observa-se o forte protagonismo da enfermagem no desenvolvimento destas, ainda que seja necessário superar as questões mencionadas anteriormente. Tal movimento requereria a adoção de um movimento dialógico, no qual a população negra possa ter vez, voz e história, principalmente no ato educativo, propondo rupturas com ações educativas verticalizadas e procedimentais que têm marcado a trajetória do campo da educação em saúde. A sistematização dos desenhos das práticas educativas realizadas pode ser melhor observada no Quadro 3, a seguir.

Quadro 3-Desenho das práticas educativas

\begin{tabular}{|l|l|l|l|l|}
\hline Tema & Participantes & Referenciais teóricos & Recursos & Estratégias \\
\hline Anemia falciforme & Quilombolas & $\begin{array}{l}\text { Manual de Educação em } \\
\text { Saúde e Autocuidado na } \\
\text { Doença Falciforme; } \\
\text { Carta de Ottawa }\end{array}$ & $\begin{array}{l}\text { Cartazes, } \\
\text { imagens, vídeos e } \\
\text { folders }\end{array}$ & Dinâmica \\
\hline $\begin{array}{l}\text { Doenças Sexualmente } \\
\text { Transmissíveis }\end{array}$ & Quilombolas & Não mencionado & $\begin{array}{l}\text { Cartazes, folders e } \\
\text { preservativos }\end{array}$ & $\begin{array}{l}\text { Palestra e } \\
\text { demonstração }\end{array}$ \\
\hline $\begin{array}{l}\text { Planejamento familiar e } \\
\text { Doenças Sexualmente } \\
\text { Transmissíveis }\end{array}$ & Mulheres de Terreiro & $\begin{array}{l}\text { Guia Prático para as } \\
\text { Estratégias de Saúde da } \\
\text { Família }\end{array}$ & Não mencionado & Não mencionado \\
\hline
\end{tabular}

Fonte: Os autores (2018).

Pressupõe-se que a forte presença de estudos realizados em quilombos ou terreiros pode ser atribuída à realidade propícia para o desenvolvimento de ações que se dirijam à população negra, não apenas pelo fato desta ser majoritária nesses espaços, mas porque é nesses lugares que pesquisadores sentem menor resistência para o desenvolvimento de recursos para tais habitantes, atenuando, assim, o paradigma ocidental, que opera predominantemente com suas ferramentas biologicistas, ora orientados por pressupostos eugênicos, ora dispersos na ideologia de uma suposta democracia racial dos serviços de saúde.

Além disso, cabe destacar as possíveis limitações desta revisão sistemática. Ao optar-se pelo uso de descritores em detrimento de palavras-chave e pela seleção de artigos científicos avaliados por pares e publicados em periódicos, excluíram-se outras experiências de pesquisadores(as) negros(as) que ainda não repercutiram nesses veículos. Experiências no campo da educação popular em saúde, que, inclusive, envolvem produção de materiais educativos, a exemplo dos desenvolvidos pela Rede Nacional de Religiões Afro-Brasileiras e Saúde ${ }^{46}$, não foram captadas. Sugere-se, para revisões futuras, a examinação de materiais publicados em livros e sites de referência na temática, tal como se mostrou fundamental a inserção da Revista da ABPN nesta revisão.

\section{Considerações Finais}

A produção científica da temática de educação em saúde relacionada à saúde da população negra vem ocorrendo de forma heterogênea nos últimos anos, nas variadas regiões do país e encontra-se dispersa entre periódicos das áreas da educação, educação em Saúde e interdisciplinar.

Nota-se uma presença significativa de estudos com populações quilombolas e comunidades tradicionais de terreiro, acompanhada também por uma tendência vanguardista da enfermagem nas ações educativas com a população negra. São necessários mais estudos para elucidar o quanto se trata de uma predominância de área ou se tal fenômeno está associado ao fato de ser a enfermagem a área, entre as ciências da saúde, que contém, em sua composição, mais profissionais negros(as) e, por isso, maior sensibilidade a essa questão.

Verifica-se a dificuldade de interpenetração de referenciais teóricos e pedagógicos, do campo da educação, na sustentação das práticas educativas em saúde, atribuída tanto às disputas internas no campo 
da educação em saúde, quanto ao próprio distanciamento imposto pelo caráter fragmentado do saber biomédico na constituição das profissões da saúde.

Por fim, sugerem-se a cooperação e a integração científica entre as distintas áreas do saber, de forma a subsidiarem a produção de conhecimento teórico e experiências práticas que superem a tradição do campo diante da população negra, oferecendo outras práxis, que considere o sujeito negro protagonista de seus caminhos e do cuidado de sua saúde.

\section{Referências}

1. Ministério da Saúde (BR). Secretaria de Gestão Estratégica e Participativa. Departamento de Apoio à Gestão Participativa. Política Nacional de Saúde Integral da População Negra: uma política para o SUS. 2 ed. Brasília: O Ministério; 2013.

2. Ponte CF, Falleiros I, organizadores. Na corda bamba de sombrinha: a saúde no fio da história. Rio de Janeiro: Fiocruz/COC; Fiocruz/EPSJV; 2010.

3. Pôrto Â. Fontes e debates em torno da saúde do escravo no Brasil do século XIX. Rev Latinoam Psicopatol Fundam [Internet]. 2008 dez. [citado em 2018 nov. 14];11(4):726-34. Disponível em: https://bit.ly/2mfaGPY.

4. Kodama K. Os debates pelo fim do tráfico no periódico O Philantropo (1849-1852) e a formação do povo: doenças, raça e escravidão. Rev Bras Hist [Internet] 2008 set. [citado em 2018 nov. 14];28(56):407-30. Disponível em: https://bit.ly/2mvVw9c.

5. Kodama K. O doutor Audouard em Barcelona (1821) e a repercussão de sua tese sobre a febre amarela no Brasil. Rev Latinoam Psicopatol Fundam [Internet]. 2008 dez. [citado em 2018 nov. 14];11(4):805-17. Disponível em: http://www.scielo.br/scielo.php?script=sci arttext\&pid=S1415$47142008000500007 \& \operatorname{lng}=p t \& \operatorname{lng}=\mathrm{pt}$.

6. Corrêa M. As ilusões da liberdade: a escola Nina Rodrigues e a antropologia no Brasil. 3 ed. rev. ampl. Rio de Janeiro: Fiocruz; 2013.

7. Freyre G, Cardoso FH, Fonseca EN da, Tuna GH. Casa-grande \& senzala: formação da família brasileira sob o regime da economia patriarcal. 51 ed. São Paulo: Global Editora; 2006.

8. Silva EG, Fonseca ABC. Ciência, estética e raça: observando imagens e textos no periódico O Brasil Médico, 1928-1945. Hist Ciênc Saúde - Manguinhos [Internet]; 2013 jun. [citado em 2019 set. 30];20(suppl.1):1287-313. Disponível em: http://www.scielo.br/scielo.php?script=sci arttext\&pid=S0104-59702013000501287\&lng=en\&nrm=iso\&tlng=pt.

9. Damasco MS, Maio MC, Monteiro S. Feminismo negro: raça, identidade e saúde reprodutiva no Brasil (1975-1993). Rev Estud Fem [Internet]. 2012 abr. [citado em 2018 nov. 14];20(1):133-51. Disponível em: https://bit.ly/2IENXgk.

10. Silva EG, Fonseca ABC. A construção da raça nacional: estratégicas eugênicas em torno do corpo da mulher. In: Batista LE, Werneck J, Lopes F, organizadores. Saúde da População Negra. Brasília, DF: ABPN; 2012, p. 240-261.

11. Quijano A. Cuestiones y horizontes de la dependencia histórico-estructural a la colonialidad/ descolonialidad del poder. Ciudad Autónoma de Buenos Aires: Clacso; 2014. Colonialidad del poder y clasificación social. p. 285-335. Disponível em: https://bit.ly/1A6IU8M.

12. Freire P. Pedagogia do Oprimido. 17. ed. Rio de Janeiro: Paz e Terra; 1987.

13. Casotti E, Brant VM, Pimenta D, Nespoli G. Educação em saúde: reflexão preliminar sobre a constituição do campo. In: VII Encontro Nacional de Educação em Ciências [Internet]; 2009 nov. [citado em 2018 nov. 28]; Florianópolis: UFSC; 2009. Disponível em: https://bit.ly/2naNjrj.

14. Gomes MCPA. Projeto Ylê ayié yaya ilera (Saúde plena na casa desta existência): equidade e integralidade em saúde para a comunidade religiosa afro-brasileira. Interface [Internet]. 2010 jul. [citado em 2018 nov. 28];14:663-72. Disponível em: http://www.scielo.br/scielo.php?pid=S1414-

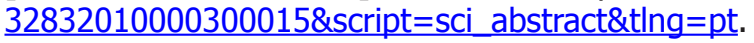

15. Ministério da Saúde (BR). Guia prático do programa saúde da família [Internet]. Brasília: O Ministério; 2001. Disponível em: https://bit.ly/2mJI2qq. 
16. Vasconcelos EM. Educação popular: de uma prática alternativa a uma estratégia de gestão participativa das políticas de saúde. Physis Rev Saúde Coletiva [Internet]. 2004 maio [citado em 2018 nov.

28];14:67-83. Disponível em: http://www.scielo.br/pdf/\%0D/physis/v14n1/v14n1a05.pdf.

17. Meneses RCT, Zeni PF, Oliveira CCC, Melo CM. Promoção de saúde em população quilombola nordestina: análise de intervenção educativa em anemia falciforme. Esc Anna Nery [Internet]. 2015 jan. [citado em 2018 nov. 28];19(1):132-9. Disponível em: https://bit.ly/2mLrNcp.

18. Passos TS, Hora AB, Paixão ALSS, Santos J, Almeida-Santos MA, Oliveira CCC. Educação em saúde para prevenção de infecções sexualmente transmissíveis em comunidades quilombolas. Rev Enferm UFPE on line [Internet]. 2017 out. [citado em 2018 nov. 28];11(10):3965-70. Disponível em: https://bit. ly/2mmcKpM.

19. Ministério da Saúde (BR). Secretaria de Atenção à Saúde [Internet]. Departamento de Atenção Especializada. Manual de educação em saúde. Vol 1, Autocuidado na doença falciforme. Brasília: 0 Ministério; 2008. Disponível em: https://bit.ly/2183cyh.

20. Fry P. O significado da anemia falciforme no contexto da 'política racial' do governo brasileiro 1995-2004. Hist Cienc Saúde - Manguinhos [Internet]. 2005 ago. [citado em 2018 nov. 28];12(2):347-70. Disponível em: https://bit.ly/2mmeeAm.

21. Diniz D, Guedes C, Trivelino A. Educação para a genética em saúde pública: um estudo de caso sobre a anemia falciforme. Ciênc. Saúde Coletiva [Internet] 2005 maio [citado em 2018 nov. 28];10(2):365-72. Disponível em: http://www.scielo.br/pdf/csc/v10n2/a14v10n2.

22. Bidinotto $A B$, D'Ávilla OP, Martins AB, Hugo FN, Neutzling MB, Bairros FS et al. Autopercepção de saúde bucal em comunidades quilombolas no Rio Grande do Sul: um estudo transversal exploratório. Rev Bras Epidemiol [Internet] 2017 mar. [citado em 2018 nov. 28];20(1):91-101. Disponível em: https://bit. Iy/2mKmQAY.

23. Silveira CL, Budó MLD, Ressel LB, Oliveira SG, Simon BS. Apoio social como possibilidade de sobrevivência: percepção de cuidadores familiares em uma comunidade remanescente de quilombos. Ciênc Cuid e Saúde [Internet]. 2011 fev [citado em 28 nov 2018];10(3):585-92. Disponível em: http:// periodicos.uem.br/ojs/index.php/CiencCuidSaude/article/view/17190.

24. Rodrigues SA, Lucas MG, Cerqueira STS, Braga AS, Vaz LG. Educação em saúde em comunidades quilombolas. Rev Gaúcha Odontol [Internet]. 2011 jul. [citado em 2018 nov. 28];59(3):445-51. Disponível em: https://bit.ly/2mHGL3h.

25. Freire P. Pedagogia da autonomia: saberes necessários à prática educativa. São Paulo: Paz e Terra; 2006.

26. Mangini Bocchi SC, Angelo M. Entre a liberdade e a reclusão: o apoio social como componente da qualidade de vida do binômio cuidador familiar-pessoa dependente. Rev Lat Enfermagem [Internet]. 2008 fev. [citado em 2018 nov. 28];16(1):15-23. Disponível em: http://www.scielo.br/scielo. php?pid $=$ S0104-11692008000100003\&script $=$ sci abstract $\&$ tIng $=$ pt.

27. Valla VV. Apoio social e saúde: buscando compreender a fala das classes populares. In: Costa MV, organizador. Educação popular hoje. São Paulo: Loyola; 1998. p. 79-151.

28. Anjos JCG, Silva SB. São Miguel e Rincão dos Martimianos: ancestralidade negra e direitos territoriais. Porto Alegre: UFRGS; 2004.

29. Lages SRC. Saúde da população negra: a religiosidade afro-brasileira e a saúde pública. Psicol Argum [Internet]. 2012 abr. [citado em 2018 nov. 28];30(69):401-10. Disponível em: https://periodicos.pucpr. br/index.php/psicologiaargumento/article/view/23295/22368.

30. Alves MC, Seminotti N, Jesus JP. Produção de saúde em uma comunidade tradicional de terreiro de matriz africana: o sujeito bio-mítico-social. Rev ABPN [Internet]. 2017 nov. [citado em 2018 nov. 28];9(23):194-222. Disponível em: https://bit.ly/2NYssoq.

31. Santos BS. A gramática do tempo. São Paulo: Cortez; 2006.

32. Mignolo WD. Histórias locais: projetos globais: colonialidade, saberes subalternos e pensamento liminar. Belo Horizonte: UFMG; 2003.

33. Hall S. A identidade cultural na pós-modernidade. Rio de Janeiro: DP\&A; 2005.

34. Morin E, Matos D. Introdução ao pensamento complexo. Lisboa: Instituto Piaget; 2003. 
35. Bâ AH. A tradição viva. In: Ki Zerbo J, organizador. História geral da África I: metodologia e pré-História da África. Brasília: Unesco; 2010. p.167-212.

36. Bastide R. Religiões africanas e estruturas de civilização. Afro-Ásia [Internet].1968 [citado em 2018 nov. 28 ];(5-6):5-16. Disponível em: https://bit.ly/2ldbcOA.

37. Santos BS. Para uma sociologia das ausências e uma sociologia das emergências. Rev Crítica Ciênc Sociais [Internet]. 2002 out. [citado em 2018 nov. 28];237-80. Disponível em: http://www. boaventuradesousasantos.pt/media/pdfs/Sociologia das ausencias RCCS63.PDF.

38. Mendes VS, Costa CS, Ribeiro RLR. Racismo biológico e suas implicações no ensinar-cuidar a saúde da população negra. Revista ABPN [Internet] 2015 mar. [citado em 2018 nov. 28];7(16):190-213. Disponível em: https://bit.ly/2lcZKCy.

39. Santili PGJ, Tonhom SFR, Marin MJS. Educação em saúde: algumas reflexões sobre sua implementação pelas equipes da Estratégia Saúde da Família. Rev Bras Promoç Saúde [Internet]. 2016 dez. [citado em 2018 nov. 28];29(Supl):102-10. Disponível em: https://bit.ly/2nhi5Pt.

40. Fernandes MCP, Backes VMS. Educação em saúde: perspectivas de uma equipe da Estratégia Saúde da Família sob a óptica de Paulo Freire. Rev Bras Enferm [Internet] 2010 jul. [citado em 2018 nov. 28];63(4):567-73. Disponível em: http://www.scielo.br/pdf/reben/v63n4/11.pdf.

41. Rocha HHP. A higienização dos costumes: educação escolar e saúde no projeto do Instituto de Hygiene de São Paulo (1918-1925). Campinas: Mercado de Letras; 2003.

42. Mai LD. Análise da produção do conhecimento em eugenia na Revista Brasileira de Enfermagem REBEn, 1932 a 2002 [tese na Internet]. Ribeirão Preto: Universidade de São Paulo; 2004 [citado em 2018 nov. 28]. Disponível em: https://bit.ly/2INV5qX.

43. Kobayashi EM, Faria L, da Costa MC. Eugenia e Fundação Rockefeller no Brasil: a saúde como proposta de regeneração nacional. Sociologias [Internet] 2009 jul. [citado em 2018 nov. 28];22:314-51. Disponível em: https://bit.ly/2/KBgRi.

44. Cota RMM. Pobreza, injustiça, e desigualdade social: repensando a formação de profissionais de saúde. Rev Bras Educ Médica [Internet]. 2007 nov. [citado em 28 nov. 2018];31(3):278-86. Disponível em: http://www.scielo.br/pdf/rbem/v31n3/10.pdf.

45. Lopes F. Para além da barreira dos números: desigualdades raciais e saúde. Cad Saúde Pública [Internet] 2005 out. [citado em 2018 nov. 28];21(5):1595-1601. Disponível em: http://www.scielo.br/ scielo.php?pid=S0102-311X2005000500034\&script=sci abstract\&tlng=pt.

46. Revista Laroiê. Rio de Janeiro: Projeto Caravana do Axé; 2012. Disponível em: http://bvsms.saude.gov. br/bvs/publicacoes/laroie.pdf. 